\title{
Art and technology: archiving video games for humanities research in university libraries
}

\author{
Kelli Wood AND David S. Carter
}

\begin{abstract}
ver the past half-century video games have become a significant part of our cultural environment, in part, by leading advances in both technology and artistic innovation. In recent years librarians and researchers have recognized these games as cultural objects that require collection and curation. Developing and maintaining collections of this fast moving and somewhat ephemeral media, however, poses challenges due to constantly advancing technology and a corresponding lack of consistent terminology. This article addresses the literature and critical issues surrounding collections of video games within libraries and presents a case study of the University of Michigan's Computer and Video Game Archive (CVGA), one of the largest academic archives of its kind. Moreover, video games are situated in a humanistic approach to the field of game studies as the article draws on the relevance of methods from art history and film studies.
\end{abstract}

\section{Introduction}

In April 1962 the first issue of the newsletter for the Digital Equipment Computer Users' Society announced both the establishment of a "program library" at the Digital Equipment Corporation (DEC) and the nascent popularity of the video game SPACEWAR at MIT (see Fig. 1). The program library would be managed by Beverly Clohset, a graduate of Central Michigan University with an interest in mathematics, and its purpose was to test and catalogue programs written for DEC's PDP-1 computer for the benefit of users. ${ }^{1}$ In the same month, Steve Russell and fellow MIT students were perfecting SPACEWAR, one of the first examples of a video game as we understand them today (see Fig. 2). Collaborators Dan Edwards and Martin Graetz reported to Decuscope newsletter editor Elsa Newman: "...SPACEWAR is an exciting game for two players, many kibitzers, and a PDP-1. The game starts with each player in control of a spaceship (displayed on PDP's scope face) equipped with propulsion rockets, rotation gyros, and space torpedos." By the summer on 1962 the inventors of SPACEWAR dispersed to different institutions, bringing copies of the video game with them. Graetz reported that program tapes were already showing up all over the country on any research computer with a CRT -- perhaps copies obtained through the DEC library. ${ }^{2}$

The 1962 Decuscope newsletter elucidates how the proliferation of new formats of information and the need for libraries to store and circulate that media responded to the co-evolution of computer technology and early video game development. Over half a century later, video games have blossomed into one of the most prevalent forms of media in the world and remain at the forefront of not only technological, but also artistic, innovation. As a result, university libraries began including video games in their collections to support research across disciplines as well as for their entertainment value. This article considers the state of current university library collections of video games and includes a review of recent literature of the topic that addresses cataloging, selection criteria, circulation, and the creation of game laboratories. It proceeds with a case study of the University of Michigan library's Computer \& Video Game Archive, including concerns and best practices for archiving technology, lab set up and operations, and interdisciplinary pedagogy and research. Finally, the article examines the
1. Decuscope: Information for Digital Equipment Computer Users 1, no. 1 (April 1962): 1-4.

2. J. M. Graetz, "The Origin of Spacewar," Creative Computing 7, no. 8 (August 1981): 66 
DFCUSCOPF

INFORMATION FOR DIGITAL EOUIPMENT COMPUTER USERS

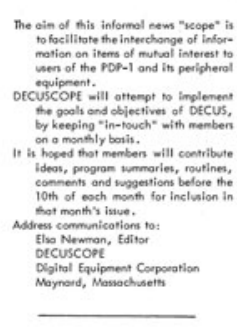

EXECUTIVE BOARO MET APRIL 4, '62

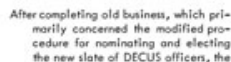

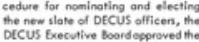

neme DECU.

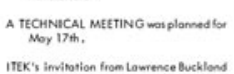

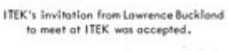

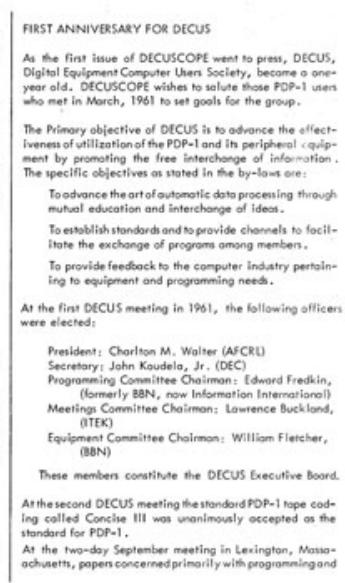

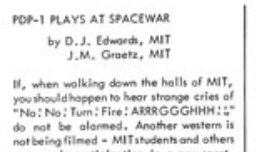

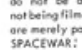

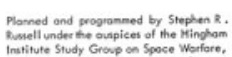

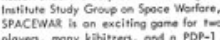


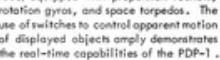
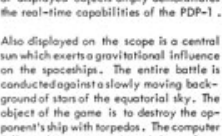

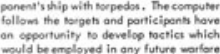

in spoce.

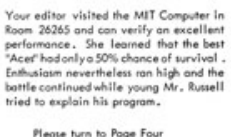

Meove num to Pogen four

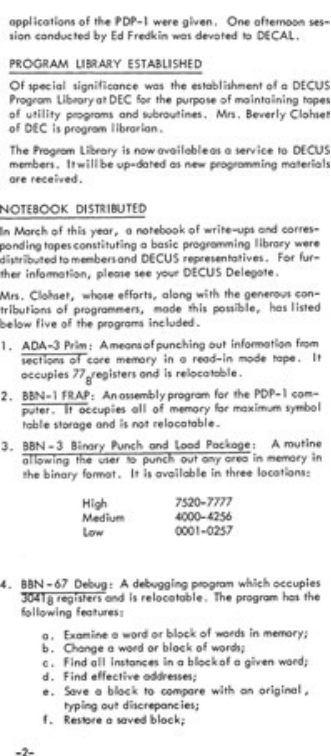

$-3$

Fig. 1. The first issue of Decuscope: Information for Digital Equipment Computer Users, April 1962.

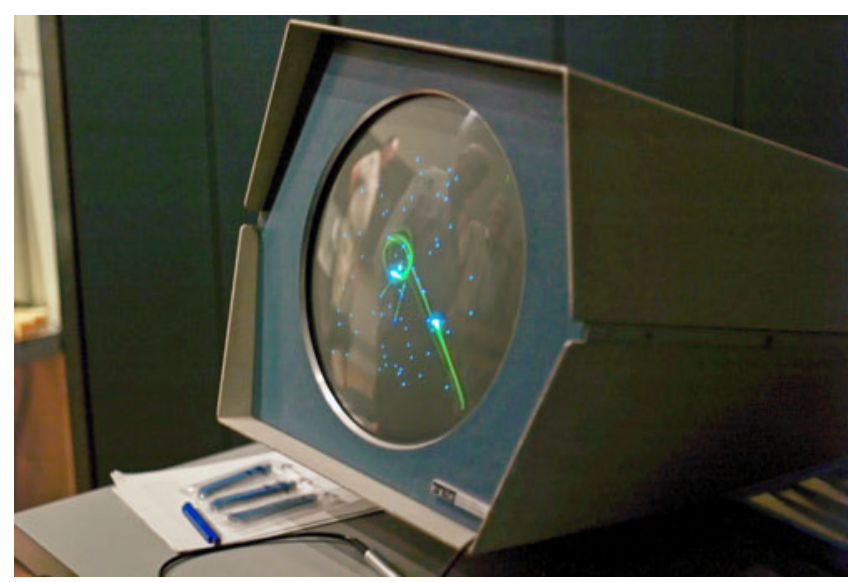

Fig. 2. Spacewar! running on the PDP-1 at The Computer History Museum. Photograph by Joi Ito, CC-BY-2.0.

relevance of libraries in fostering research on video games in the arts and humanities disciplines. By situating video games within the emerging and evolving field of game studies and including methodologies from film studies and art history, the article concludes by calling for the necessity for the incorporation of still and video image captures of video games within image databases produced by visual resources centers.

\section{Video games in university libraries}

In the introduction of Jesper Juul's now essential text Half-Real: Video games between real and fictional worlds, Jull defines games as 'transmedial,' meaning that the system and rules of a game permutes across media -- such as being able to play chess on either a wooden board or a computer. ${ }^{3} \mathrm{~A}$ key challenge in collecting and cataloguing video games in libraries is managing their transmedial state and various formats across interfaces. Video games as a popularly understood category appear on cartridges played on early consoles such as the Atari 2600 or Nintendo Entertainment System, programs and disks run on computers such as the Commodore 64 or Apple IIGS, CDs run on fifth and sixth generation on consoles such as PlayStation or Xbox, handheld devices from the Nintendo

3. Jesper Juul, Half-real. Video Games between Real Rules and. Fictional Worlds (Cambridge MA: The MIT Press, 2005), 7. 
Game Boy to the Switch, server based games and digital downloads for computers, phones, and tablets, as well as immersive virtual reality environments such as the CAVE platform.

Greta de Groat has charted the history of cataloguing practices for the varied formats of video games in U.S. libraries, including changes in ALA and Library of Congress rules, noting that rapidly evolving technology has often resulted in a lag in accessioning and accurately and consistently describing of video games in catalogues. De Groat concludes that the collocation of video games has suffered from a lack of consistent terminology, for example that the Library of Congress makes a distinction between video games and computer games, but that recent updates to RDA and MARC standards are improving. ${ }^{4}$ Zach Welhouse, Jin Ha Lee, and Jennifer Bancroft have proposed a regular and controlled vocabulary for describing the narrative features of video games in order to catalogue them according to their plot. ${ }^{5}$

While some libraries began to casually include video games into their collections, others actively and intentionally built collections of games. In 2007, Danielle Kane, Catherine Soehner, and Wei Wei documented the creation of a game lab and library collection at the University of California, Santa Cruz, in response to the creation of the a new interdisciplinary degree in game design. The library started with a core of 15 games on reserve on different consoles. Librarians had selected the games based on the quality of content (judged by the technical merit and aesthetic quality of graphics, sound, gameplay, and value), as well as the considerations of maintenance, ease of use, cost, and language. ${ }^{6}$ Elizabeth Tappeiner and Catherine Lyons examined a number of libraries in order to create selection criteria for the acquisition of games, including practical considerations of equipment, the usefulness for teaching objectives, relevance of content for real world skills, and the historical and cultural value of video games. ${ }^{7}$ Because the prevalence of violent and sexual content in video games may raise issues of censorship for librarians wishing to provide access to materials needed for research, dedicated content specialists should be relied upon to make decisions about which games to acquire. ${ }^{8}$

Mary Laskowski and David Ward identify three main reasons for incorporating video games into academic library collections: to support faculty research, to support classroom instruction, and for the entertainment and curricular needs of students. They call for a collaboration between these areas, suggesting that libraries can become an important nexus for this field of research. ${ }^{9}$ Faye Chadwell has agreed, asserting the centrality of video games to the mission of academic libraries despite a few studies that have suggested their inclusion is untenable given widespread budgetary constraints. ${ }^{10}$ Cécile Swiatek and Myriam Gorsse have also argued for the inclusion of games in libraries, suggesting librarians shift focus away from entertainment toward interactive learning that can be facilitated by new staff roles such as 'Game Manager' and 'Game Designer,' while public librarian Ball Gallaway provides a guide for organizing an entertainment-leaning collection of video games. ${ }^{11}$

Diane Robson and Patrick Durkee's approach focuses on the development of collections in academic libraries. They summarize that promoting access to digital and internet games, in particular curated collections of independent and artistic games, will be crucial for the future of studying games as the field evolves technologically. ${ }^{12}$ Carleton University Librarians Emma Cross, David Mould, and Robert Smith also discuss how to approach collections management in the face of a shift from console based gaming to newer technologies and online platforms. In particular they note how digital rights management will be a key factor in the future of collecting video games. ${ }^{13}$

Over a dozen major university libraries have actively publicized video games collections in recent years. Stanford University has pioneered video game collections in academic libraries, archiving over 3,200 video games and numerous consoles in their Media \& Microtext Center. Stanford also houses the Stephen Cabrinety archives, which includes computer hardware, hand-held games, literature, and documents on the formative years of the microcomputing gaming industry. ${ }^{14}$ Between 2007 and 2010 several public university libraries in the United States began collecting and circulating video games, including the University of Michigan, University of North Texas, the University of Oregon, and UC Santa Cruz. ${ }^{15}$ In the United Kingdom in 2008, Nottingham Trent University, Bath Spa University and the National Media Museum in Bradford collaborated to create a digital collection of video games. ${ }^{16}$ In Canada, the University of Calgary created
4. Greta de Groat, "A History of Video Game Cataloging in U.S. Libraries," Cataloging \&

Classification Quarterly 53, no. 2 (2015): 135-156.

5. Zach Welhouse, Jin Ha Lee, and Jennifer Bancroft, “"What Am I Fighting For?": Creating a Controlled Vocabulary for Video Game Plot Metadata.' Cataloging \& Classification Quarterly 53, no. 2 (2015): 157-189.

6. Danielle Kane, Catherine Soehner and Wei Wei, "Building a Collection of Video Games in Support of a Newly Created Degree Program at the University of California, Santa Cruz", Science \& Technology Libraries, 27, no. 4 (2007): 83.

7. Elizabeth Tappeiner and Catherine Lyons, "Selection Criteria for Academic Video Game Collections", Collection Building, 27, no. 3 (2008): 121-125.

8. As has been the case at the library at Carleton University, see Emma Cross, David Mould, and Robert Smith, "The Protean Challenge of Game Collections at Academic Libraries," New Review of Academic Librarianship 21, no. 2 (May 4, 2015): 137.

9. Mary Laskowski and David Ward, "Building Next Generation Video Game Collections in

Academic Libraries," Journal of Academic Librarianship 35, no. 3 (May 2009): 267-73.

10. Faye Chadwell, “What's Next for Collection Management and Managers? Games and Gaming in Academic Libraries." Collection Management 36, no. 4 (2011): 198-202.

11. C. Swiatek and M. Gorsse, "Playing games at the Library: Seriously?" LIBER Quarterly 26, no. 2 (2016): 83-101; Beth Gallaway Game On! Gaming at the Library (New York, NY: Neal-Schuman Publishers, 2009).

12. Diane Robson and Patrick Durkee, "New Directions for Academic Video Game Collections: Strategies for Acquiring, Supporting, and Managing Online Materials," Journal of Academic Librarianship 38, no. 2 (Mar. 2012): 79-84.

13. Emma Cross, David Mould, and Robert Smith, "The Protean Challenge of Game Collections at Academic Libraries," New Review of Academic Librarianship 21, no. 2 (May 4, 2015): 140.

14. "Guide to the Stephen M. Cabrinety Collection in the History of Microcomputing, ca. 1975-1995." Stanford University, 
the Games and Related Media Collection to house video game consoles from Pont to Intellevision and Colecovision alongside over 2000 game titles. ${ }^{17}$ University libraries have also begun incorporating popular and critically successful video games into their collections for entertainment and research, including Virginia Commonwealth University, Michigan State, and the University of Delaware. ${ }^{18}$

Shannon Farrell, Amy Neeser, and Carolyn Bishoff have conducted interview-based qualitative research on the use of video games at the University of Minnesota in order to ascertain the information and technology needs of scholars and to develop a strategic approach to video games services that could be extrapolated to other libraries. ${ }^{19}$ Their findings noted that scholars in the humanities and social sciences had a strong need for books and journals in addition to video games themselves to support research, and they conclude that collaborative and a multidisciplinary approach to collection development would best serve universities as a whole. Moreover they note that an unwillingness or inability for video game companies to partner with academic libraries is an issue needs to be further explored, but libraries can partner with one another to overcome barriers to access.

A key point of agreement in the existing literature on video games in academic libraries is the relevance and importance of the establishment of game laboratories in order to facilitate the archiving and upkeep of game consoles and equipment, the circulation of video games, and a point of access for both entertainment and teaching. The Computer \& Video Game Archive, at the University of Michigan is one of the oldest and most expansive of such game labs, and as a case study, it could be considered a model for the implementation of video game collections at other universities.

\section{The Computer \& Video Game Archive, at the University of Michigan}

The UM Computer and Video Game Archive (CVGA) opened in the fall of 2008 (see Fig. 3). It currently houses nearly 8,000 games from over seventy different systems, as well as board and card games, tabletop roleplaying games, and various secondary sources and ephemera. In 2017 the CVGA welcomed nearly 5,000 visitors and recorded usage of over 16,000 items from the collection. The CVGA collects digital and analog games from the early 1970s to the present day. Open to the public Monday through Friday, the main CVGA archive room is located in the basement of the Duderstadt Center, a digital commons on the University of Michigan's North Campus that also houses the Art, Architecture \& Engineering Library. In the archive room, users are able to browse the collection

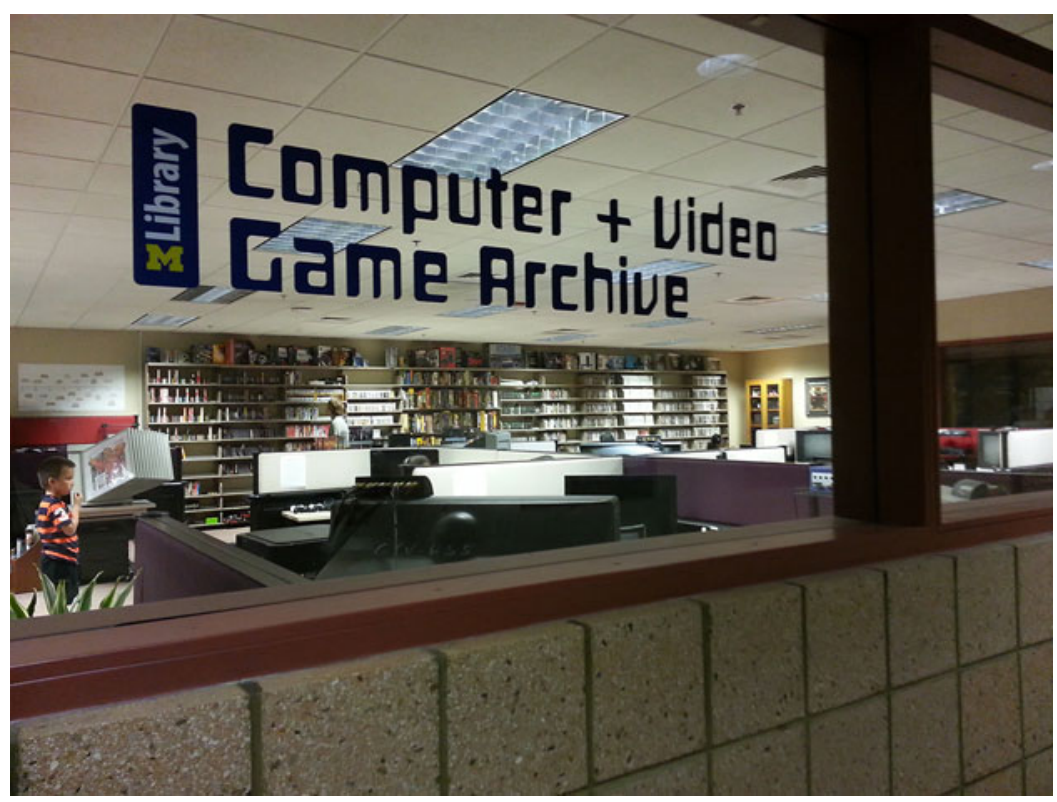

Manuscripts Division, Special Collections M0997, https://oac. cdlib.org/findaid/ark:/13030/ kt529018f2/.

15. "University of North Texas Gaming Collection," https://www. library.unt.edu/collections/ media-library/gaming; Laurie Bridges, Uta Hussong, and Margaret Mellinger, "Circulating Video Game Collections in the Academic Library," (Corvallis, OR: Oregon State University Libraries, 2008), https://ir.library.

oregonstate.edu/concern/parent/ 9p290b95r/file_sets/9k41zf996;

Danielle Kane, Catherine Soehner and Wei Wei, "Building a

Collection of Video Games in Support of a Newly Created Degree Program at the University of California, Santa Cruz", Science \& Technology Libraries, 27, no. 4 (2007): 77-87.

16. David Crookes, "Curators at The British Library have begun the process of archiving videogame websites," https://www. independent.co.uk/life-style/ gadgets-and-tech/news/britishlibrary-starts-videogame-websitearchive-project-6858507.html . 17. Chris Nelson, "Gaming Reaches into Far Corners of Academic World as $\mathrm{U}$ of $\mathrm{C}$ Builds Huge Collection," Calgary Herald (Mar. 16, 2015), http://

calgaryherald.com/news/localnews/gaming-reaches-into-farcorners-of-academic-world-as-uof-c-builds-huge-collection

18. Brian McNeill, “VCU Libraries Launches Collection of Critically Acclaimed Video Games," VCU News (blog), Nov. 6, 2014, http:// news.vcu.edu/article/VCU

Libraries_launches_collection_of critically_acclaimed_video ; “Univ. of Delaware Video Game Collection," https://library.udel. edu/filmandvideo/video-gamecollection/; "Michigan State Video Game Labs," https://lib.msu.edu/ gaming/ .

19. Shannon Farrell, Amy Neeser, and Carolyn Bishoff, "Academic Uses of Video Games: A Qualitative Assessment of Research and Teaching Needs at a Large Research University," College and Research Libraries 78, no. 5 (2017): 675.

Fig. 3. Computer \& Video Game Archive at the University of Michigan. 
of games on the shelves and play the games at one of twenty different gaming stations (including a semi-private room for motion and VR gaming and large tables for playing board games). Since the CVGA maintains both software and hardware for the digital games, the collection is limited to in-house use. During hours of operation the archive is attended to by one or more CVGA staff, typically student workers or the CVGA Manager (a full-time staff position). ${ }^{20}$

\section{Acquisitions, collection, and preservation}

The CVGA main collections include primary sources in the form of console games, handheld games, microcomputer games, as well as secondary sources of books about games (including academic monographs, player's guides, game novelizations, and graphic novels) and gaming magazines. ${ }^{21}$ The archive includes over fifty different gaming platforms, ranging from the Atari 2600 and TRS-80 to the Microsoft Xbox One and Sony PlayStation 4 (see Figs. 4-6). ${ }^{22}$ While the majority of the collection is focused on English language games, the early primacy and influence of Japanese games and producers is also reflected in the archive (see Fig. 7). All games have been cataloged and can be found through the library's discovery system. Items for the collection are selected by the Video Game Archivist in accordance with the CVGA collection policy. ${ }^{23}$

Issues regarding the collection and preservation of video games often mirror the issues involved in any archival collection, but there are several concerns related to these particular formats. As with many popular culture collections, it can be difficult to acquire old items in good condition. While some types of vintage games can be acquired through online retailers and auction houses, others can be difficult to track down. Particularly elusive, for example, are microcomputer games from the 1970 s and early 1980s -- an era in which some main modes of distribution were via plastic bags at flea markets or pages executable code (intended to be retyped by hand) published in computer magazines. Donations can be helpful in such instances, as has been the case with nearly half of the UM CVGA collection. Moreover, a representative game archive will not only need to manage many different media formats (solid state cartridges, cassette tapes, magnetic discs, optical discs, digital downloads, etc.), but it must also maintain the equipment on which to access and play the games. Some of these formats are more volatile than others: while game cartridges from the 1970s and 1980s have

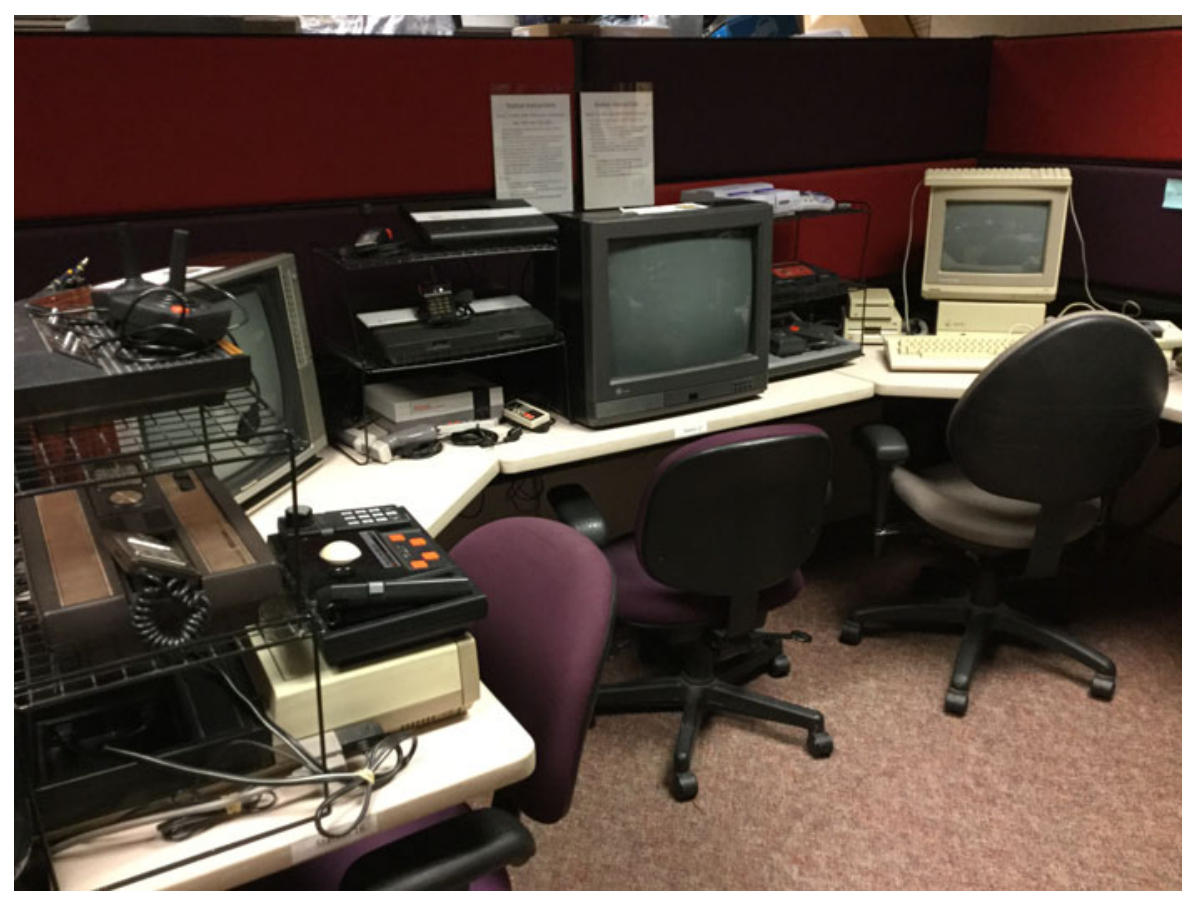

Fig. 4. Video game consoles and microcomputers from the 1970s and 1980s at the Computer \& Video Game Archive, University of Michigan.
20. For the CVGA's use policy and day-to-day operations, see: https:// www.lib.umich.edu/computervideo-game-archive/cvga-usepolicies

21. For an extensive-though not exhaustive-list of gaming systems and microcomputers available in the CVGA, see: https:// www.lib.umich.edu/computervideo-game-archive/cvgaavailable-systems

22. For a full list of the holdings of the CVGA, visit: https://www.lib. umich.edu/computer-video-gamearchive/cvga-available-systems 23. See https://www.lib.umich. edu/mlibrary-collections/ collection-area-computer-andvideo-game-archive 


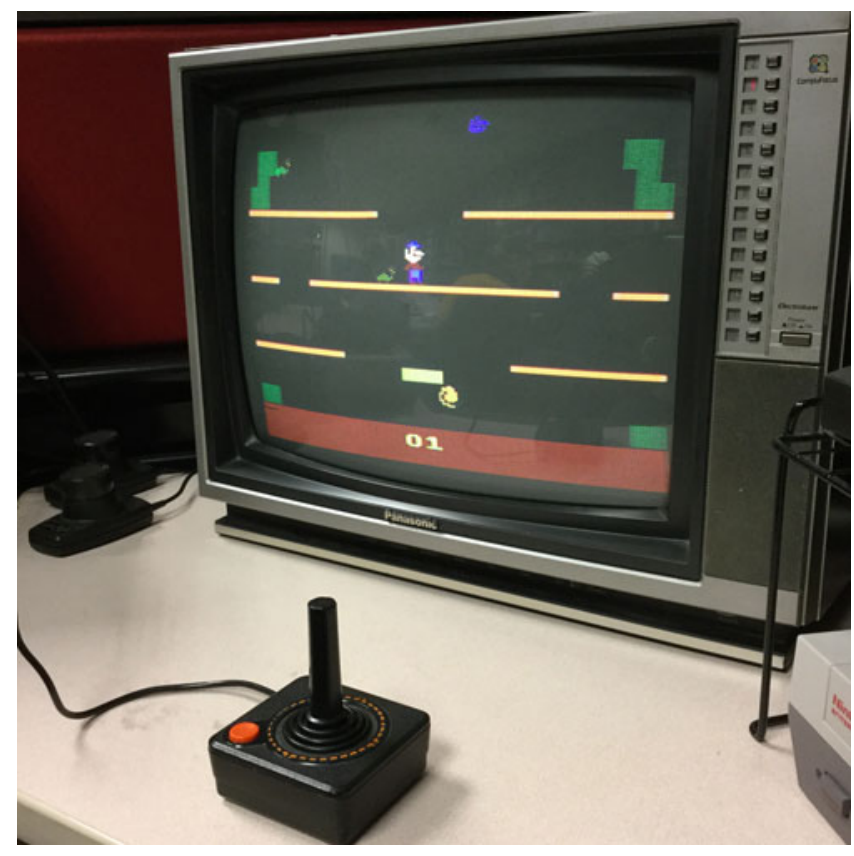

Fig. 5. Mario Bros (1983) played on the Atari 2600, at the Computer \& Video Game Archive, University of Michigan.

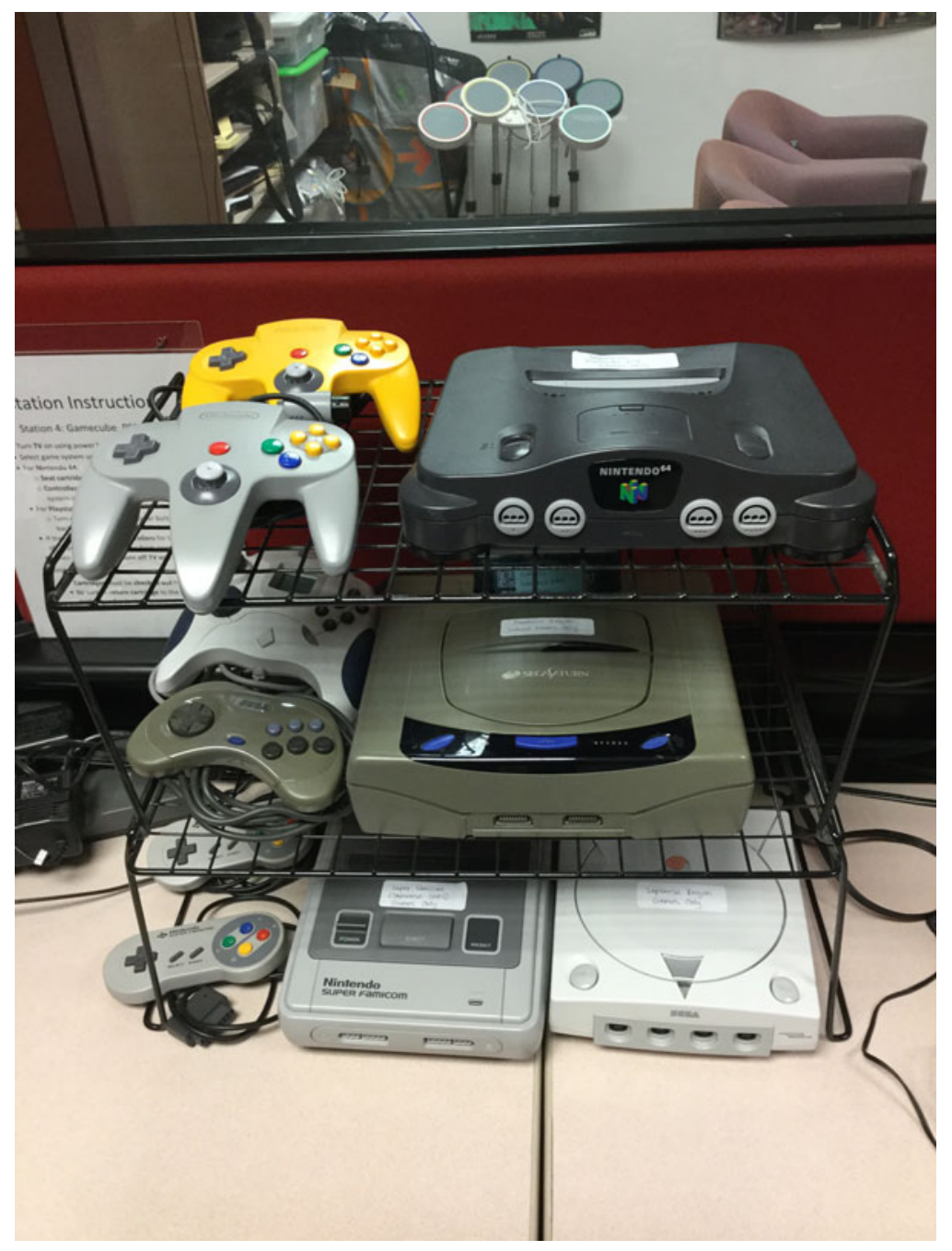

Fig. 6. Video game consoles from the 1990s at the Computer \& Video Game Archive, University of Michigan. 


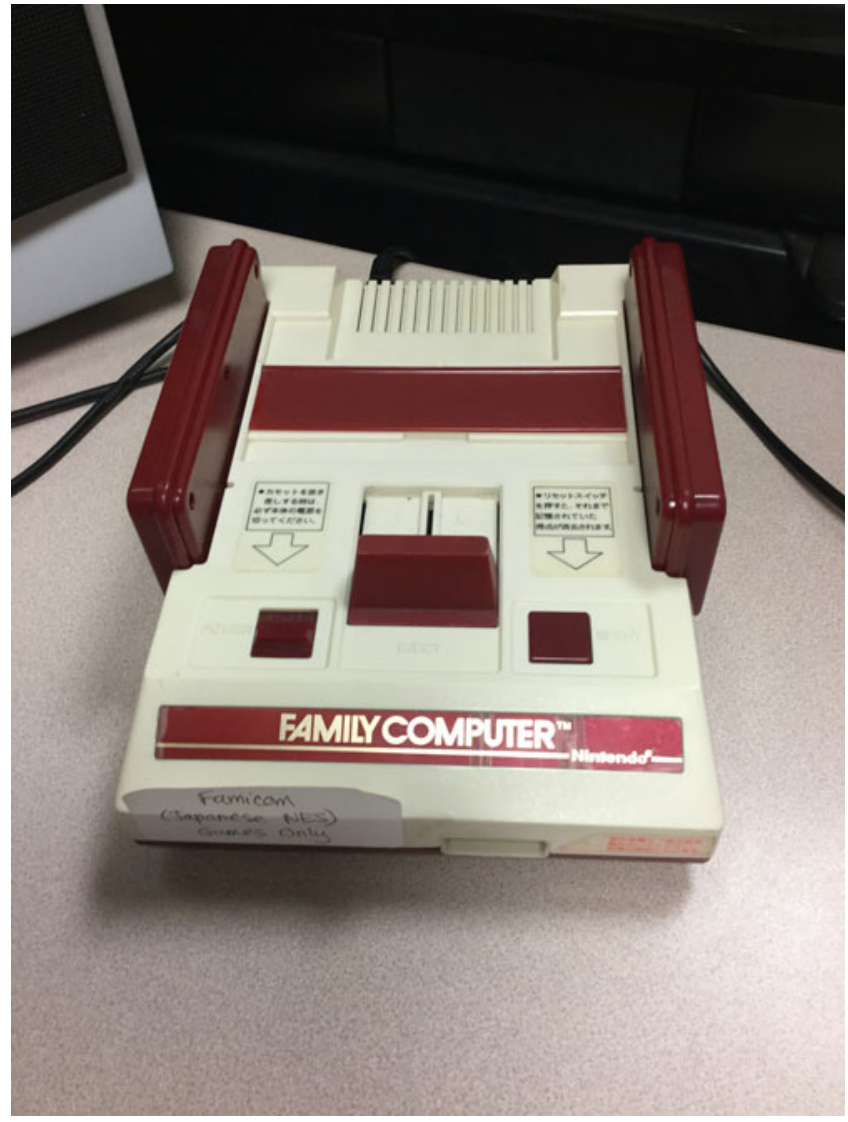

Fig. 7. Nintendo Famicom, released in Japan in1986, at the Computer \& Video Game Archive, University of Michigan.

proven to be remarkably hearty, each time a game is loaded from a cassette tape may be the last.

When the CVGA was planned, a conscious decision was made to allow for the indiscriminate playing of the games within the confines of the CVGA space, and as such materials are stored and used on site and cannot be checked out of the library (see Fig. 8). While a more "white glove" approach to the archive could have been taken, UM librarians felt it was important to have the games be played and experienced as determined by the archive users, allowing for exploration and discovery. Inevitably this has led to some drawbacks, as games that are played are games that suffer from wear, especially in the case of controllers. Strategies for mitigating wear and loss have included storing optical materials in archival sleeves, learning basic repair techniques, and keeping a cache of replacement systems and controllers.

\section{Mission and uses}

The primary mission of the CVGA is to support the teaching and research interests of students, faculty and staff at the University of Michigan as it relates to games. To this end, the CVGA hosts classes related to game studies and game creation, and supports class-directed and independent research. As game studies is a multidisciplinary field, the students and researchers come from departments all over campus, including art, music, history, literature, education, psychology, and many others. ${ }^{24}$ Frequently instructors and researchers focus on games as creative or artistic works, taking the games as texts to be studied in much the same way as one would examine novels, plays, poetry, movies, or paintings. The extensive and historical nature of the CVGA's collections has made it possible for researchers to explore such research topics as race and ethnicity in all of the FIFA games, or race as an option in character generation in dozens of different role playing games (both in digital and analog format). Other topics explored using the CVGA collections include the role of time in games, using the Legend of Zelda
24. For a list of courses that have made use of the CVGA, see: http:// guides.lib.umich.edu/c.php?g= 282989\&p=5955147 

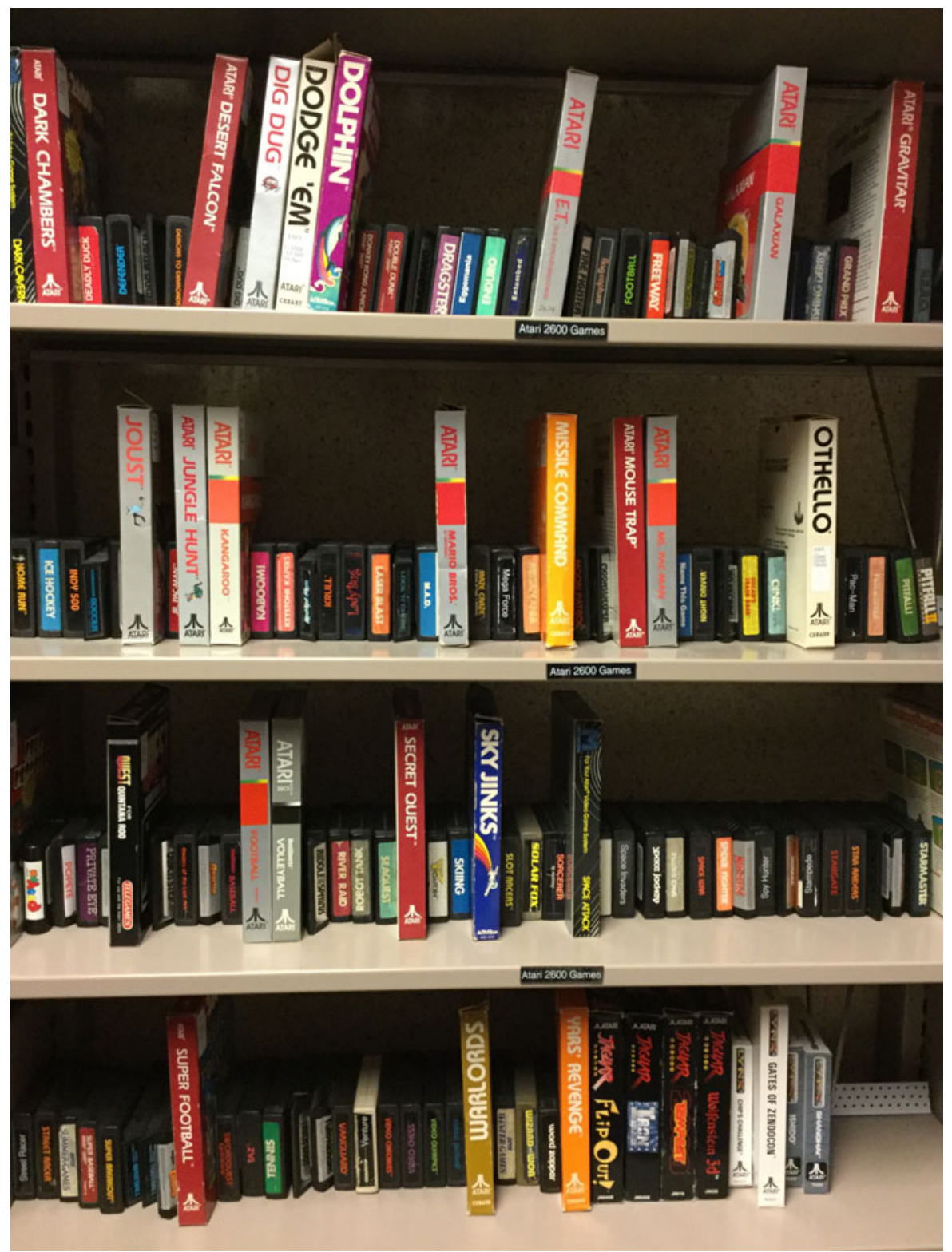

Fig. 8. On site shelving of video game cartridges in the Computer \& Video Game Archive University of Michigan.

series as a case study, and games based on historical traumas, particularly the American Civil War.

Games can also be used as examples or enticements to learn about other related topics. At the University of Michigan, a popular course in the music department introduced non-music majors to concepts of music theory and analysis through video game music. Another example was a class on the History of the Samurai, where students studying the depiction of samurai in literature and other popular creative works used the CVGA for a class session on samurai in video games. In another instance, a senior-level game creation course in the computer science department, where students studying advanced team programming used the collection of the CVGA for inspiration. Other creative uses of the CVGA have involved using the games in the collection as tools for an unassociated field, such as in an engineering class wherein students studied the effects of texting while driving by having their subjects attempt to play a racing game while using their cell phones, or a joint project between the CVGA and the Language Resource Center that used board games to improve the instructional English skills of graduate student instructor hopefuls for whom English was not their primary language. 
When the CVGA is not reserved for classroom or research use, it is also available to students, faculty, staff and the general public for open recreational gaming. Such use is encouraged, allowing for people to play old games they may have only heard about, or get together with friends between classes to play popular games such as first person shooters such as Halo or Call of Duty, music games such as Guitar Hero, or sports games such as the FIFA series. This serves not only the entertainment needs of students, but it also introduces them to the CVGA as a resource that they may later employ for a class project.

\section{Arts and humanities research on video games}

Video game labs such as the Computer \& Video Game Archive at the University of Michigan have the potential to shape and support emerging fields of research under the umbrella of game studies. Game studies is a relatively new subfield that focuses on the play of games in and of itself, considering the cultural activities and material artifacts of games that intersect between many disciplines, from anthropology and history to textual studies and computer science. Dutch historian Johan Huizinga wrote perhaps the seminal work in the creation of game studies, Homo Ludens: a study of the play element in culture. ${ }^{25}$ Huizinga sought to answer the question 'what is the nature of play and what is its significance in society?' He concluded that play is indeed serious and fundamental to culture.

Authors looking to sociology, such as Roger Caillois, have interpreted games as cultural performances, representations of society in which members produce their individual and collective identities. ${ }^{26}$ Norbert Elias and Eric Dunning situated the role of sport in society within a framework of mimetic activities in spare time, looking to an Aristotle's considerations of mimesis in relation to poetry and drama. 27

The innovation and proliferation of video games in the past decades has initiated further debates and lines of inquiry within the field of game studies. A central methodological question for game studies has been the debate between the approaches ludology vs. narratology. Narratology seeks to see games through the meanings they create, the narrative they disseminate, while ludology focuses on the gameness of the game, its structure, rules, mode of play, and how that creates meaning. Joost Raessens and Jeffery Goldstein's early Handbook of computer game studies emphasizes the necessity of a multidisciplinary approach to games, beginning with a historical and technological lens on the development of video games, moving to a designer's perspective on game creation, to a clinical psychological approaches to the effects of playing video games alongside empirical laboratory studies, and finally considering issues of aesthetics and identity. ${ }^{28}$ In particular Anna Everett's chapter, "Serious Play: Playing with Race in Contemporary Gaming Culture" and her subsequent work asks salient questions about the moral implications of pleasurable racism in video games, the embodied experiences of minority players of video games, and the promulgation of racial narratives. ${ }^{29}$

Humanities fields, including cinema and media studies, design studies, visual and material culture, and art history, have also begun to generate significant scholarship within game studies. Alexander Galloway has taken a philosophical approach to video games within media studies, teasing apart how the formal qualities of video games have not only an aesthetic, but also political, impact, such as in the case of the origin of the first person shooter and the gaze. ${ }^{30}$ Jasmina Kallay has looked at video game's impact on cinema, questioning the divide placed between the two categories on the basis of interactivity in her dissection of narrative and special architectures. ${ }^{31}$ Part II of Mark J.P. Wolf and Bernard Perron's The Routledge companion to video game studies further tackles "Formal aspects" such as art, color, and perspective, focusing on methods from media studies. ${ }^{32}$ While the category of art is rarely defined or analyzed from an art historical perspective, the repeated query "Are video games art?" pervades many discussions of formal qualities and aesthetics. Brian Schrank's Avant-Garde videogames: Playing with technoculture begins with a resounding affirmative, stating that indeed video games are art before exploring radical and avant-garde games influenced by contemporary art movements. ${ }^{33}$ John Sharp in Works of game: On the aesthetics of games and art takes the discussion further, showing how contemporary artists have coopted the medium, formal qualities, and aesthetics of video games in their artworks. ${ }^{34}$
25. Johan Huizinga, Homo Ludens: A Study of the Play Element in Culture (London: Routledge \& Kegen Paul, 1949).

26. Roger Caillois, Man, Play and Games, trans. by Meyer Barash (London: Thames and Hudson, 1962).

27. Norbert Elias and Eric Dunning, eds., The quest for excitement: sport and leisure in the civilizing process (Oxford; New York: B. Blackwell, 1986).

28. Joost Raessens and Jeffery Goldstein, eds., Handbook of Computer Game Studies (Cambridge, Mass: MIT Press, 2005).

29. Anna Everett, Digital Diaspora A Race for Cyberspace (Albany: SUNY Press, 2009).

30. Alexander Galloway, Gaming: Essays on Algorithmic Culture, Electronic Medications 18 (Minneapolis: University of Minnesota Press, 2006).

31. Jasmina Kallay, Gaming Film: How Games are Reshaping Contemporary Cinema (New York: Palgrave Macmillan, 2013).

32. Mark J.P. Wolf and Bernard Perron, eds., The Routledge Companion to Video Game Studies (New York: Routledge, 2014). There have been several earlier iterations of this work, see: Mark Wolf and Bernard Perron, eds., The Video Game Theory Reader (New York: Routledge, 2003).

33. Brian Schrank, Avant-Garde Videogames: Playing with Technoculture (MIT Press, 2014). 34. John Sharp, Works of Game: On the Aesthetics of Games and Art (MIT Press, 2015). 
While several museums have opened in order to preserve computer and video games as historical artifacts, such as the Computerspielemuseum in Berlin, VIGAMUS: The Video Game Museum of Rome, the International Center for the History of Electronic Games at the Strong National Museum of Play, or "Hot Circuits: A Video Arcade" the first video game exhibit curated by Rochelle Slovin at the American Museum of the Moving Image, recent exhibitions have sought to place video games within the discourse of art and contemporary art history. For example, The art of video games exhibition and catalogue by Chris Melissinos and Patrick O'Rourke at the Smithsonian American Art Museum resolved the tension between video games as a popular and commercial medium and their visual, formal, and interactive potentials as art forms. ${ }^{35}$ The upcoming exhibition at the Victoria and Albert Museum, Videogames: Design/play/disrupt will focus on the design process of contemporary video game art. Smaller galleries and exhibitions too have emphasized video games as art, such as the Video Game Art Gallery in Chicago, IL and its companion journal, The VGA reader.

In the context of video games as art, libraries have the potential to enable and shape the field based on the resources they provide and how they curate knowledge. Brena Smith has already noted the important role that libraries can play in supporting the field of game studies, focusing on computer science and digital game design, while Henry Lowood has compared the development of game studies to the formation of the history of science as an academic discipline. 36 Libraries can facilitate research on video games within the fields of game studies and humanistic and artistic inquiry in a number of ways. For instance, the creation of subject guides that include not only technical and computer studies approaches in relation to video games, but also that include information about art and design and historical approaches to game studies across media can help broaden students and researcher's horizons. Furthermore, the co-housing of recent exhibition catalogues and academic journals on game studies such as Game studies, Ludica, International journal of computer games technology, or Games and culture would allow for easy access to complementary scholarship. Finally, in light of current research on video games as art, video game librarians could partner with colleagues in visual resource centers to incorporate stills and videos from video games into image databases of artworks. This could be achieved with through high quality scans of books and catalogues or through the use of game capture devices. The creation of clear guidelines for formal analysis for describing these game images from the outset would best enable users to properly understand the context of the excerpts and provide consistent metadata. Although, like film, such images raise legal concerns about their use, properly catalogued images of video games could be considered under the College Art Associations guidelines for fair use for teaching and research. ${ }^{37}$

\section{Conclusion}

University collections of video games attend to the dual functions of library and archive. The archives strain to achieve a prescient historical distance from the artifacts of video games in an archeology of knowledge dictated by our own interests and discourses and also to preserve the frangible technology that is inseparable from the aesthetic content of games. ${ }^{38}$ Simultaneously the library circulates and contextualizes video game objects to meet the needs of students and faculty members, not neutrally providing entry into to a well formed discipline, but shaping the nature of our understanding of video games. Libraries provide the crucial spaces and technologies necessary for teaching and the intellectual materials necessary to formulate and conduct research in the field of game studies itself. Ultimately university library collections of video games and game labs such as the Computer and Video Game Archive at the University of Michigan serve an essential function for cutting edge pedagogy and research, and a continued focus on giving access to multidisciplinary materials alongside video games themselves will ensure their continued academic relevance.
35. Chris Melissinos and Patrick O'Rourke, The Art of Video Games: From Pac-Man to Mass Effect (New York: Welcome Books, 2012).

36. Brena Smith, "Twenty-First Century Game Studies in the Academy: Libraries and an Emerging Discipline," Reference Services Review 36, no. 2 (2008): 205-20; Henry Lowood, “Game Studies Now, History of Science Then," Games and Culture 1, no. 1 (January 2006): 78-82.

37. College Art Association, "The Code of Best Practices in Fair Use in the Visual Arts." http://www. collegeart.org/programs/caa-fairuse/best-practices .

38. On historical distance and discourse of the archive, see: Michel Foucault, The Archaeology of Knowledge (Paris: Éditions Gallimard, 1969). 
Kelli Wood

Assistant Professor, Postdoctoral Scholar

University of Michigan

Dept. of the History of Art, Society of Fellows

110 Tappan Hall

855 South University Avenue

Ann Arbor, MI 48109

USA

woodkell@umich.edu

David S. Carter

Video Game Archivist, Reference Services Librarian

University of Michigan Library

2321C Duderstadt

Ann Arbor, MI 48109

USA

superman@umich.edu 